to, or accompanying, certain cardiac or aneurismal diseases, it may be considered as originating in an imperfect elaboration of the blood-plasma, or other reparative constituent; the constitutional vice in the organs engaged being related to defective assimilation and renovation, rather than to channe connected with the process of decay, the result of decomposition and rearrangement of the elementary constituents, independent of any further addition $a b$ extra. The term "degeneration" as now used, appears to imply but one purely chemical source of textural change, but may with equal (if not greater) probability be referred to inadequate renewal or reproduction of tissue, arising out of abnormal conditions of cell-growth, and defective formative power in the in-coming nutritive pabulum. Chemical authorities are at issuc as to whether or not azotised and non-azotised bloodconstituents are respectivcly convertible; the animal organism being, however, pre-eminently a reducing apparatus. Now, althourh the myoline of muscular fibre becomes replaced by oily particles, in fatty metamorphosis, we have hereby no positive (only analogical or presumptive) proof of a conversion of the former into the latter having taken place. An excess of adipose matcrial, favourable to fatty deposition, may obtain from its decreased consumption, through inaction of the liver, lungs, skin, and kidneys. Again, excess of oily constituents mily result from conversion of the more animalised components of the tissues, in their removal from the system by the agency of the liver, as stated by $M$. Bernard. This, however, is effected by glandular activity, and hears little analogy to that change, which ensues in or ranic matter removed out of the sphere of action of the living organism. In the latter case, the play of chemical affinities, operative in the conversion of fibre into fat or adipocere, would seem to require the presence and co-operation of air and moisture. This eonversion does not ensue when, as in the process of preserving meat, oxygenation is prevented lyy the exclusion of atmospheric air; the changed condition of the fibrous and other tissues by tic cooking process not of itself precluding, though retarding decomposition. Fatty transformation may be said to take place, for the most part, under very different conditions, too numerous to specify here, but sufficiently obvious in the hody during life. IBlood-filmrin differs from the tilorinous basis of muscle, according to Strecker, in being more highly azotised; in its hehaviuur with a dilute acidulous solution, in which it gelatinises, but does not dissolve; and in not being dissolved hy an excess of alkaline precipitant; the reverse holding with reference to the fibrin of muscle, which approximates to albumen in composition and chemical relations. The fibrin of hlood would appear to he the nutritive constituent of the simple fibrous membranes, such as the elastic arterial tissi:c, pericardium, etc.; its amount in the blood being adequate to this, but not sufficient for the growth and repiair of the muscular system; while the lingec proportion which the allominous constituent of the hlood licars to the other ingredients, seems to denote it to be the agent for the fulfilment of the latter office. Now, if we consider the blood to lie defective in the amount or clalioration of the allouminous constituent, the other ingredients saicl by Heller to he required in the process of healthy cellular nutrition-the calcarcous salts and oily jabulum-being cither normal or aberrant, we may account for the falling away in the cardiac and vascular tissues, simply as the result of mal-assimilation-to employ a term lonis in use, and conveniently expressive of a recondito oileriation.*

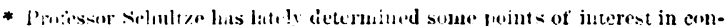
nevion with this sulpient.

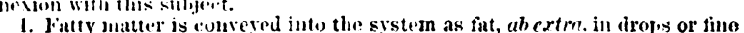
divisions:

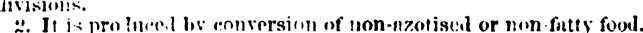

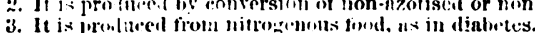

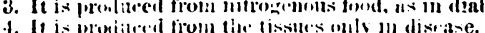

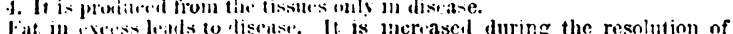

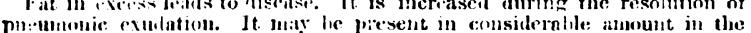

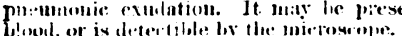

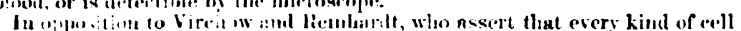

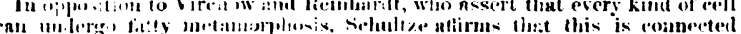

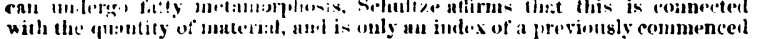

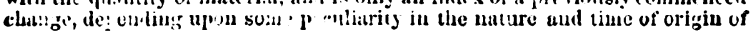

It would be interesting to determine whether the salts of lime and the organic acids are defective in, or absent from the urine of those in whom deposits of cholesterine and calcareous matter take place in the valves, on the surface, or in the walls of the heart, as well as throughout the circulatory apparatus. We want precise information on these most important points. In the meantime, we can trace to some extent the disjoined and remote links in this morbific chain: witness the association and interdependence between malaria, rheumatism, abnormal deposits in the tissues, and defective nutrition, secretion, and excretion, through biliary, splenic, and renal remora, as evinced in some of the preceding illustrations. The centre of the circulatory apparatus of course bears, in many cases, tho greatcst strain on its function; and, in consequence of its primary importance to the organism, its disease more immediately leads to a fatal issue. The tendency to this result may be often masked till death take place; and it may be doubted whether we possess any certain or even probable indication of the imminence of this event, those premonitory symptoms assigned as diagnostic being often absent up to the last moment of life, and the post mortem examination giving the first demonstration of the existence of disease. The cases of the late Dr. Chalmers and of other eminent men are memorable instances in point.

With respect to fibrinous or albuminoid deposits in the parictes of the heart or blood-vessels, or on their lining membrane, there are many facts, derivable from humoral pathology, which would indicate such deposits to be of not unfrequent occurrence, and not unlikely to materially interfere with the circulatory function. It may be recollected, that the fibrinous constituent of the blood is far from being uniform in its chemical composition, under various morbid phases; and to this deviation, as well as to its varying proportions in the circulating fluid, is referrible occasional structural regression in the tissues. The muscular fibres of the heart and blood-vessels approach blood-fibrin in composition, though not identical with it; and the heart, in common with other involuntary muscles, has little cellular tissue entering into its structure. Those diseases, such as rheumatism, scorbutus, certain forms of chlorosis, etc., in which the amount of fibrin in the blood varies, are not unfrequently associnted with eardiac, ancurismal, or hacmorrhagic affections; these latter discases being no doubt closely connected with structural deviations in the tissues. or lining membrane of the vascular apparatus.

[To be continued.]

\section{ON DISTICHIASIS.}

By WhITE COOPEI, Esq., F.R.c.s., Seninr Surgeon to the North Loudon Eye Infirmary, and Ophthahuie: Suyeon to St. Mary's II ospital.

Sryce the pullication of my communication on Distichiasis, in the Associatios Jovksal of February lsth, my attention has been called to a very alle paper by Mr. Wilde, of Dublin, on "the Causes and Treatment of Entropium and 'Trichiasis",* and I regret that, when writing on the sulject, I should have overlooked the following remarks, as they are the result of extensive experience ; for, in Ireland, affections of the eyclids appeir to be very common among the lower orders. Mr. Wilde says: "The fact of an additional growth of hairs has been denied; and it is asserted that, 'although they issue from the wrong place, and grow

the nucleus. Fat may pre-cexist in the eells. as well as arise from the trans. the nuclens. Fnt muy pre-(xist, in thre echls as well as arige from the transformation of protein constituents. The evolution of cells int, granular ifut-
containing) (cells is not a refingrals inetumory liose. The ritality of a cell, us

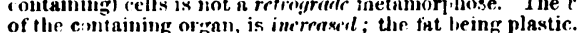

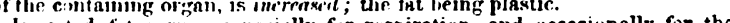
Inyested fat serves especially for respiration. and occasionally for the

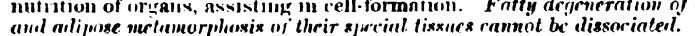

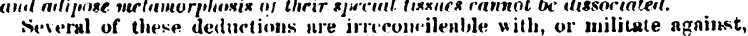
Severul of these deductions ure irceon ilenble with, or milisate agninst,
the prevalent doctrine respecting "fitty degeneration"; and serve to conthe prevalent doctrine respecting "fatty legeneration"; and serve to con-
tirm the views alose tuken, us regrards the modo of production of this firm the views alos
abluonmal condition. * Contronutions to Ophtlabmic Surgery. Sari Ir. Dublin, 1814. 
in a wrong direction, they are not new productions, but merely natural cilia, the bulbs of which have been displaced by disease affecting the border of the eyelid'; and had I not several preparations in my possession, which show an undoubted additional growth of these hairs, I should be very slow in differing from this, one of the highest living authorities upon ophthalmic surgery. In these cases, however, I not only examiued the tarsal margins minutely after their removal, but counted the cilia, and they invariably amounted to more than what occurs in health; although it must be acknowledged that the number varies even in a healthy or natural condition.

"In psorophthalmia, and particularly in tinea palpebrarum, when inflammation attacks the whole margin of the eyelid (especially the upper), and the cutis swells considerably, while small abscesses form round the roots of the individual hairs, and the entire surface in some cases presents a condylomatous appearance, the intersiaces between the cilia enlarge from the unhealthy deposit in the part; .so that the natural position of these hairs is reversed, being then more divergent where they pierce the skin than at the roots; and they likewise exhibit a bushy, very irregular and distorted appearance, in a well marked triple or quadruple row. Now, although the original disense that produced this state may be speedily removed, still the fibrous deposit along the margin of the lid which altered the relation of these hairs, remains to a certain extent, and keeps up their deformity, or unnatural or distorted position, in whole or in part, so as subsequently to produce the disease called trichiasis, the apex of the line of hairs being then at their roots along the cartilage, and the base at their fine extremities."

The following mode of treating single hairs when inverted, is well worthy of attention:-

"In such cases, placing the horn spatula within the lid, I make an incision with a small knife down to the root of the inverted lash; and, having waited till the hamorrhage has ceased, I apply a point of nitrate of silver by means of a porte-caustique down to the bottom of the wound, and then remove the lash; it seldom fails, but frequently it destroys two or three of the neighbouring cilia."

I avail myself of this opportunity of stating, with refercnce to Captain T., whose case I described, that the lids close with facility, and the cornea have become clear; he is able to read with comfort in any amount of light, and much improvement has taken place in his appearance.

19, Br.rkeley Square, March 5th, 1853.

\section{DISLOCATION BACKWARDS OF THE HEAD OF THE HUMERUS.}

\section{By EDWARD JACKSON, M.B.}

Sir A. Cooper and Mr. Listor allude to dislocation backwards of the head of the humerus as an exceedingly rare accident.

Ilaving lately met with a very well marked example, I have thought that it may be useful to the profession to give an account of the peculiarities of the case, and of the manner in which reduction was accomplished.

CAsE. The subject was a strong muscular man, aged about 35 years, who had for some years suffered from epilepsy. During one of these attacks, falling suddenly, he sustained a dislocation of his left shoulder.

The following condition of the limb was presented. The arm was removed from the side, but the patient could with considerable effort raise it to a horizontal position. On comparing the two shoulders, there was a greater prominence observable posteriorly on the left side, but not so much so as one would have expected to find in an accident of this kind. There was little, if any, falling down of the head of the humerus, as in dislocation downwards; nor was there so great a projection of the acromion process; yet this was tolerably conspicuous anteriorly at the point of its junction with the claricle. The head of the bone could not be felt in the axilla. The tendon of the biceps, arising from the coracoid process of the scapula, together with that of the coraco-brachialis, were felt anteriorly like tense cords stretching from above downwards. But the most remarkable diagnostic sign of this dislocation was a circular depression on the anterior aspect of the joint; and when the fingers were somewhat forcibly pressed into the centre of this depression, the whole circle of the glanoid cavity could be distinctly felt. This at once identified the accident as dislocation backwards.

Reduction was attempted by extension from the upper and lower arm, whilst an effort to replace the bone by rotation outwards was made ; but after persisting for a considerable time, and using great force, no movement resulted. Having given up the attempt to reluce by this method, we had recourse to a different plan. The forearm was flexed, whilst slight extension was made at the same time, and the bone simultaneously rotated outwards; and thus, with litile effort, the reduction was effected.

It appears that the chief obstacles to reduction in this peculiar dislocation consisted in the violent tension of the tendons of the biceps, coraco-brachialis, and pectoralis major muscles.

Ecclesfield, near Sheflield, Feb. $18 j 8$.

\section{BIBLIOGRAPHICAL NOTICES.}

Six Lectures or Materia Medica, and its Relation to the Animal Economy. Delivered before the Royal College of Physicians in 1852. By Jour Spurcis, M.D. 8vo., pp. 204. London : 1852 .

SoMe years ago, an annual course of "Six Lectures on MIateria Medica" was established by the Royal College of Physicians, for the purpose not only of explaining the sources, preparations, and properties of medicines, but also of unfolding the principles which should be observed in their administration. These principles, of course, are founded upon a much broader basis than mere pharmacy, and indeed can only be deduced from a study of the science of medicine in all its relations, including anatomy and physiology. Dr. SPU RGIN proposes, in this course of lectures, "to examine certain principles and laws which the animal economy presents to our observation, and by the operation of which it is constantly preserved and perpetuated". These laws and principles he deduces chiefly from an examination of the nature and constitution of the blood, and the part which it performs in the economy of animal life. The subject of these lectures, therefore, is not (as the title would lead the reader to expect), what is commonly understood by the term materia medica; but it is, in fact, the physiology of the blood, and its connexion with pathology and therapeutics.

A disquisition on such a subject, from the pen of so accomplished a physician as Dr. Spurgin, cannot but be interesting to the profession; and, as the author's views are in some important points perfectly original, differing essentially indeed from the commonly received opinions, we feel it incumbent upon us to give a short analysis of the contents of the volume.

Dr. Spurgin's theory of the animal economy is based upon the hypothesis, that "the blood, by its universal presence in the system, and in virtue of its being the very origin and source of every part, and thence of the whole bodily fabric, constitutes the very corporeal life and vital principle to which they all refer and are subordinate". By boldly assuming this theory, and investing with a material, though fluid attribute, the vital principle, the author has at once cut the Gordian knot, and banished from the vocabulary of medicine all the vague terms with which former physiologists have endeavoured to express a something which they could not comprehend, nor believe to have a material existence. If Dr. Spurgin's hypothesis be received, the terms vital principle, vis nervosa, vis medicatrix natura, materies 